\title{
Technical assistance to the interagency coordination group seeking to reduce female genital mutilation/cutting
}

Nafissatou J. Diop

Population Council

Follow this and additional works at: https://knowledgecommons.popcouncil.org/departments_sbsr-rh

Part of the Demography, Population, and Ecology Commons, Health Services Research Commons, and the International Public Health Commons How does access to this work benefit you? Let us know!

\section{Recommended Citation}

Diop, Nafissatou J. 2008. "Technical assistance to the interagency coordination group seeking to reduce female genital mutilation/cutting," FRONTIERS Final Report. Washington, DC: Population Council. 


\section{Technical Assistance to the Interagency Coordination Group seeking to reduce Female Genital Mutilation/Cutting}

\section{Frontiers in Reproductive Health (FRONTIERS), Population Council Nafissatou J. Diop}

\section{April 2008}

This study was made possible by the generous support of the American people through the United States Agency for International Development (USAID) under the terms of Cooperative Agreement No. HRN-A-00-98-00012-0 and In-house project 5800 53114. The contents are the responsibility of the FRONTIERS Program and do not necessarily reflect the views of USAID or the United States Government.

\section{(2) Population Council FRONTIIRS}




\section{BACKGROUND}

FRONTIERS has received support from USAID's "Special Initiative on FGM/C" and from the Africa Bureau for several years, enabling it to sustain an important role in promoting evidencebased strategies for abandoning the harmful traditional practice of female genital mutilation/cutting (FGM/C) in sub-Saharan Africa. Because of this range of experiences in different socio-cultural settings, USAID's Special Initiative has provided support to FRONTIERS to enable it to offer technical assistance to the Interagency Coordination Group on FGM/C. The Group was officially created in 2005 by several regional organizations in order to better collaborate and coordinate interventions against FGM/C in Africa. These organizations are the UNFPA country support team, UNICEF regional office for West and Central Africa, WHO Africa Division, and IC-AF headquarters in Addis Ababa. Given its recognized expertise, FRONTIERS was invited to join this group of multilateral organizations to provide technical assistance in achieving the following objectives:

1. Establish a collaborative network to support work within countries;

2. Develop a comprehensive program of interventions against FGM/C and other harmful traditional practices;

3. Share experiences and disseminate successful strategies, tools and information;

4. Provide technical assistance to countries to document and disseminate experiences;

5. Contribute to raising human and financial resources needed for the implementation of country interventions;

6. Support civil society organizations to better address the issue of FGM/C;

7. Build the capacity of organizations, including monitoring and evaluation;

8. Advocate for more awareness and visibility of FGM/C issues at national, regional and international levels.

\section{ACTIVITIES}

Networking and influencing the content of policy and programmatic international documents The Interagency Coordination Group is pursuing several goals in the area of research, advocacy, fundraising, and capacity building. FRONTIERS' role was to participate in these activities as opportunities and needs arise, such as in meetings and conferences, presentation of results, and assistance to agencies. Several policy and programmatic documents were developed by the UN agencies represented on the interagency group. These included: the joint policy statement against FGM/C; the coordinated strategy for the abandonment of FGM/C in one generation; the development of a road map for the elimination of $\mathrm{FGM} / \mathrm{C}$; the establishment of a boundaries surveillance system to discourage migration of families for FGM/C. Given the consultative process generally used by UN agencies, these subjects were discussed in advance within the Group and recommendations were made by the inter agency coordinating group members to the event/activity organization team at the headquarters. FRONTIERS made several contributions to the development of these documents through its participation in the group, answered positively to request for participation and provided documentation on OR results. In particular, FRONTIERS provided extensive support in the development of the interagency coordination group joint proposal for the elimination of FGM/C, its five-year plan of action and fund raising process. 


\section{Sharing lessons learned with countries}

FRONTIERS produced a folder on FGM/C that gathered together OR summaries generated during the past 10 years, a legacy document, documentation of interventions and the CD-ROM on FGM/C. Five hundred folders were produced and disseminated during regional FGM/C meetings. The folders were also sent to Anglophone and Francophone grassroots NGOs, government organizations and the coordinating focal point in the West Africa Region.

FRONTIERS attended several workshops organized by one or the other member of the Interagency Coordination Group at which it disseminated FGM/C materials, made presentations of lessons learned and explanations of what works and what does not work to West African country program managers.

\section{Technical Assistance to Mauritania}

The Interagency Coordination Group identified that Mauritania needed considerable support for its campaign against FGM/C and so assistance was requested from FRONTIERS, whose staff undertook two trips to support partners in Mauritania. UNICEF in Mauritania had received funding from the "Communidad de Madrid" in Spain to support its FGM/C work, and so FRONTIERS reviewed UNICEF's plan of action for their four priority regions and supported revision and finalization of the plan. FRONTIERS also advised development of the M\&E mechanism of the Tostan program for 30 communities, the development of indicators and a research agenda, and the development of an IEC notebook on FGM/C.

\section{Difficulties and lessons learned}

Understaffing, overloading and mobility of existing staff, insufficient funding, and a lack of engagement by several of the agencies' headquarters, and the mobility of personnel hindered implementation of activities and smooth functioning of the interagency coordinating group. FRONTIERS supported the Group in keeping open dialogue and communication between the members, and helped members to learn how to present a common view during the development of policy documents by their headquarters. 


\section{TABLE OF CONTENTS}

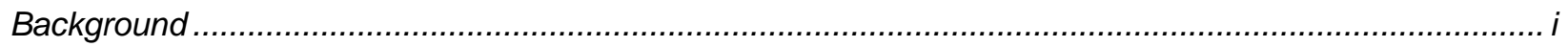

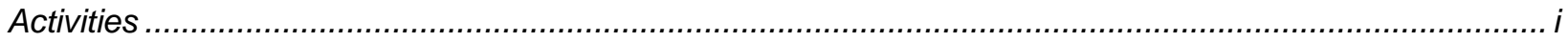

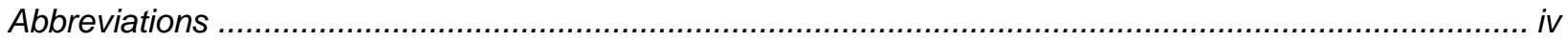

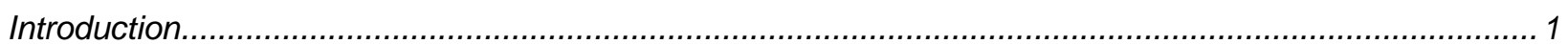

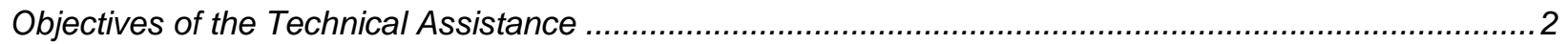

Intermediate Results Addressed ...................................................Error! Bookmark not defined.

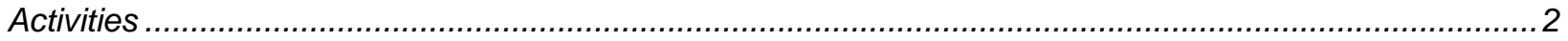

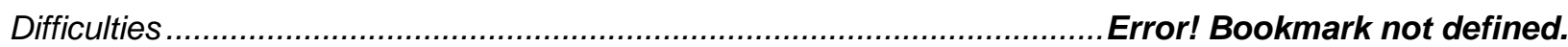

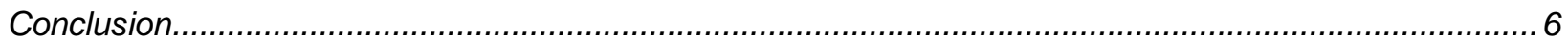




\section{AbBreviations}

IAC Inter African Committee Against Traditional Practices

CNLPE Comité National de Lutte contre la Pratique de l'Excision- Burkina Faso

CNIES Cellule Nationale d'Information, d'Education et de Communication

CPTAFE Comité de lutte contre les Pratiques Traditionnelles portant Atteinte aux Femmes

CRDH Centre de Recherche pour le Développement Humain

FGM/C Female Genital Mutilation / Cutting

GTZ Gesellschaft Fur Technische Zusammenarbeit

IEC Information Education Communication

MICS Multiple Indicators Cluster Survey

MIS Management Information System

MNG Multidisciplinary National Group

MLG Multidisciplinary Local Group

M\&E Monitoring and Evaluation

$\mathrm{MOH} \quad$ Ministry of Health

OR Operations Research

TA Technical Assistance

UNICEF United Nations Children's Fund

UNFPA United Nations Fund for Population Activities

USAID United States Agency for International Development

WHO World Health Organization 


\section{INTRODUCTION}

FRONTIERS has received support from USAID's "Special Initiative on FGM/C" and from the Africa Bureau for several years, enabling it to sustain an important role in promoting evidencebased strategies for abandoning the harmful traditional practice of female genital mutilation/cutting (FGM/C) in sub-Saharan Africa. In Mali, evaluations of strategies for 'converting' excisors and for involving health providers in promoting anti-FGM/C messages during consultations were evaluated. The former study led to a general abandonment of the strategy of converting excisors, in Mali and in other countries. The latter study led firstly to an $\mathrm{MOH}$ policy directive forbidding staff from undertaking FGM/C and secondly to a project supported by the USAID-funded PRIME II project to scale-up the training of health providers in FGM/C education. A comparative study was undertaken in clinics in Mali and Burkina Faso to observe and measure associations between type of FGM/C and their negative health outcomes among women attending for RH services; findings from this study were published in an international journal and $\mathrm{WHO}$ adapted parts of the methodology to implement its multi-center study on the medical consequences of FGM/C. In collaboration with GTZ, FRONTIERS has undertaken evaluations of the TOSTAN program in Senegal and its replication in Burkina Faso. More recently, in collaboration with UNICEF, FRONTIERS has undertaken an evaluation of the long-term impact of the public declaration of abandonment of FGM/C. Several qualitative studies have been undertaken in Burkina Faso to better understand the community's point of view, the results of which contributed to the national campaign against FGM/C. An assessment of the decline of FGM/C in Burkina Faso has also been completed and the results disseminated.

In addition, FRONTIERS has undertaken several studies in Eastern Africa (Kenya, Sudan, Ethiopia) and in Egypt to document and evaluate alternative strategies for encouraging abandonment of the practice. The CEDPA project on FGM and the Village free FGM model are both being evaluated with UNICEF funding. FRONTIERS also supports the INTACT-network for those interested in improving the application of evaluation and research methods for FGM/C. Staff from FRONTIERS are regularly consulted by organizations such as UNICEF, UNFPA, WHO, and GTZ for their expertise in the field.

Because of this range of experiences in different socio-cultural settings, USAID's Special Initiative has provided support to FRONTIERS to enable technical assistance to be offered to the Interagency Coordination Group on FGM/C. The Group was officially created in 2005 by several regional organizations in order to better collaborate and coordinate interventions against FGM/C in Africa. These organizations are the UNFPA country support team, UNICEF regional office for West and Central Africa, WHO Africa Division, and IAC headquarters in Addis Ababa. Given its recognized expertise, FRONTIERS was invited to join this group of multilateral organizations to provide technical assistance in achieving the following objectives:

1. Establish a collaborative network to support work within countries;

2. Develop a comprehensive program of interventions against FGM/C and other harmful traditional practices;

3. Share experiences and disseminate successful strategies, tools and information;

4. Provide TA to countries in order to document and disseminate experiences; 
5. Contribute to raising human and financial resources needed for the implementation of country interventions;

6. Support civil society organizations to better address the issue of FGM/C;

7. Build the capacity of organizations, including M\&E;

8. Advocate for more awareness and visibility of FGM/C issues at national, regional and international levels.

\section{Objectives of the Technical Assistance}

1. To improve the effectiveness of strategies for encouraging abandonment of FGM/C through sharing lessons learned from successful FGM/C abandonment strategies undertaken elsewhere;

2. To promote the use of existing research results and lessons learned in strategy development;

3. To support capacity building for routinely documenting experiences with implementing interventions among the country teams implementing programs against FGM/C;

4. To increase the capacity of country teams in monitoring and evaluation.

\section{ACTIVITIES}

\section{Networking and influencing the content of policy and programmatic international documents}

The Interagency Coordination Group is pursuing several goals in the area of research, advocacy, fundraising, and capacity building. FRONTIERS' role was to participate in these activities as opportunities and needs arise such as in meetings and conferences, presentation of results, and assistance to the network coordinator. The group gathered several times in order to update each member organization on the activities conducted during the past year/quarter and the proposed activities to come. Examples of the type of information shared and discussed during these meetings include:

- Mechanism to implement joint activities efficiently;

- Ideas and recommendations for the Geneva meeting to develop the revised joint policy statement;

- WHO's project for the evaluation of 27 African countries plans of action against FGM/C;

- The coordinated strategy on FGM launched by UNICEF;

- UNICEF's initiative for reinforcing the boundaries surveillance system against FGM/C in four countries around Benin;

- UNICEF's consultative meeting of academic scholars on the social convention theory and game theory, particularly suggestions to include African university scholars;

- IAC's initiative for building capacity of Anglophone and Francophone journalists on FGM issues to support country-level and regional campaigns;

- The Spanish government's willingness to fund FGM/C activities and identification of priority countries and areas; 
- UNFPA's conference to develop a road map on FGM/C; Development of the agenda, identification of presentation and field countries teams;

- UNFPA's Knowledge Asset development on FGM.

Given the consultative process generally used by UN agencies, these subjects were usually discussed in advance of the official meeting and recommendations made by the group members to the event/activity organization team at the headquarters. FRONTIERS made several suggestions to the group, answered positively to requests for participation and provided documentation.

\section{Developing a plan of action and supporting the fund raising process}

FRONTIERS provided assistance for the development of a proposal and plan of action for five years to support the Group's joint activities. Discussions took place on the mechanisms of operation of this proposal with shared responsibilities. FRONTIERS suggestion for a one-year chairing process, with each institution taking an effective role for coordinating the interagency coordinating group, was accepted and the UNICEF regional office advisor was elected to chair the interagency coordinating group for the first year.

Following finalization of the five year plan of action, FRONTIERS (on behalf of the Group) translated the proposal into English and submitted it to the USAID GLP for potential funding. During the Zero Tolerance Day meeting in Washington, FRONTIERS presented the Group's objectives and main activities. Partners from AED and UNFPA headquarters showed interest in funding the proposal.

\section{Sharing lessons learned with countries}

Production and dissemination of IEC materials

Most information generated from research and programs in the region were not in a format that would enable grass roots program managers to use the information specifically for designing, implementing and evaluating programs. FRONTIERS produced a folder on FGM that gathered OR summaries generated during the past 10 years, a legacy document, documentation of interventions and the CD-ROM on FGM. Five hundred folders were produced and disseminated during regional FGM meetings to participants. The folders were also sent to national grassroots NGOs, various governmental organizations and the coordinating focal point in the West Africa Region.

\section{Dissemination of FRONTIERS results}

FRONTIERS attended several workshops organized by members of the Interagency Coordinating Group. Dissemination of FGM/C materials, presentation of lessons learned and explanations of what works and what does not work took place. The opportunity was also taken to support the integration of these lessons within organizations' operational planning. Dissemination of results from FRONTIERS research were made at the following venues: 
- Regional meeting on holistic approaches, organized by UNICEF for program managers from NGOs and government organizations working against FGM/C in eight West African countries.

- Regional training workshop for Francophone journalists, organized by IC-AF.

- Tenth anniversary of the Malicounda declaration: a celebration of the abandonment of FGM/C by 2,400 villages in Senegal organized by Tostan and attended by the Ministry of Social Action, NGOs, parliamentarians, journalists, women's activist and communities.

- Media briefing meeting at UNESCO attended by 31 journalists from the press, radio and TV in both the private and public sectors.

- Zero Tolerance Day in Senegal attended by the Ministry of Social Affairs, managers, local women's groups and media.

\section{Technical assistance for Mauritania and Senegal}

Mauritania: The Group identified that some countries were lagging behind others in organizing national campaigns against FGM/C. Mauritania was identified as a country with a very high prevalence of FGM/C ( 3 out of 4 women are cut) and with no organized response. Assistance was requested from FRONTIERS and so staff undertook two trips in order to support partners from the government and UNICEF in Mauritania. UNICEF/Mauritania received about $\$ 800,000$ from the Communidad de Madrid in Spain to support their FGM/C work. FRONTIERS reviewed UNICEF's draft plan of action on FGM/C for their four priority regions and made suggestions for its revision and finalization. Below are the main FGM/C activities for which FRONTIERS provided technical assistance.

Assistance to the Ministry of Women Promotion, Child and the Family (MCPFEF)

- FRONTIERS participated in a workshop to develop the national plan of action organized by the Ministry with a financial support from both UNICEF and UNFPA. This workshop gathered about 50 participants from local NGOs, UN agencies, religious leaders, professional associations of midwives and doctors, and other development partners such as GTZ and the Spanish Cooperation.

- FRONTIERS presented and explained what works and what doesn't work in anti-FGM intervention to these groups.

- FRONTIERS requested WHO to disseminate the results of its research on the obstetric complications associated with FGM/C to convince medical doctors to issue a letter declaring the harmful effects of FGM/C, which would also enable the religious leaders to make a fatwa against FGM/C.

- Following the MCPFEF workshop, FRONTIERS was requested by UNICEF/Mauritania to finalize its five-year plan of action, with budget lines and key responsible agencies. The proposed coordination mechanism and activities to raise community awareness were reviewed by FRONTIERS and modified to reflect evidence-based knowledge. A plan with a budget of $\$ 2,300,000$ was developed.

- FRONTIERS provided input for the development of an Integrated Plan of Communication through a one-day working session with the IEC Coordinating Unit of the Ministry of Health. In particular, FRONTIERS recommended that FGM/C should be integrated within other $\mathrm{RH} / \mathrm{MCH}$ and development programs given the Mauritanian context rather than addressed as a stand-alone issue. 
- FRONTIERS identified several indicators for the M\&E plan and suggested research areas.

- FRONTIERS was requested to develop an IEC notebook on FGM/C with a synthesis of the situation of FGM/C in Mauritania and arguments to counter the practice, particularly on religious aspects.

\section{Assistance to the Tostan project in Mauritania}

Communidad de Madrid funded Tostan through UNICEF for the implementation of its community empowerment program in 30 communities in Brakna, a southern region. The program started in 2007 with several difficulties. The donor wanted to see indicators of changes by the end of the project, but as the Tostan baseline study did not capture these indicators, FRONTIERS undertook the following activities:

- Clarified the expectations from the Spanish partner in terms of monitoring and evaluation;

- Developed the M\&E indicators and sources of information. The MICS questionnaires were used to identify indicators that could be used for this purpose. In addition, FRONTIERS contacted the MOH and UNFPA to better understand the MOH MIS system and recommended a process to collect indicators of immunization and prenatal care for the 30 villages in which the Tostan program is being implemented.

- Visited the Tostan project in Brakna to talk with the coordinator and supervisors to assess the level of implementation of the program, understand difficulties, and made suggestions for the improvement of the project in Mauritania, where the cultural and social context is different than in Senegal.

Senegal: WHO/Senegal requested assistance from FRONTIERS to support its evaluation of the Senegal 10 year plan of action against FGM/C. This was done in preparation for a regional meeting that WHO wants to convene for all 27 countries in the AFRO region in which FGM/C is practiced. FRONTIERS worked with the Ministry of Social Affairs, which was responsible for coordination of the plan of action, to identify the key institutions, their activities, suggest a framework of analysis and gather the information.

\section{DifFICULTIES}

Insufficient mechanisms to operationalize the letter of understanding: Regional staff responsible for anti-FGM/C issues in the UN agencies are overstretched with other maternal health activities. They were not able to allocate sufficient time to the implementation of the joint plan of action of the interagency coordination group. After recognition by the group members that the proposal development phase had been too slow, FRONTIERS recommended that a consultant be appointed to maintain the flow of communication between agencies, gather information and remind each agency of its role in this joint activity. WHO accepted to support this position for 11 months, the scope of work was developed and amended by the group, and a letter of request to the WHO Africa Bureau director issued. However, the process was never completed as the WHO person in charge of FGM/C retired.

Funds: Regional offices do not have sufficient funds to implement the activities, including coordination. Therefore several planned activities were not implemented. 
Difference of vision between headquarters and regional offices: Some concerns were expressed by the group about using the social convention theory as the only model on which to base their work, as recommended by the headquarters, including: 1) lacking discussions with country-based institutions; 2) lack of African scholars from anthropology and sociology; add 3) insufficient funds for other types of strategies. The interagency group's lack of enthusiasm for this model limited the availability of funds at regional and national level.

Difficulties in planning coordinated activities: The letter of understanding for the interagency coordination group was signed by UNICEF, UNFPA and WHO at their Africa Division headquarters. However no effort was made to engage the headquarters staff working on FGM/C, and so these staff continued developing and implementing their own activities in Africa without any consultative process with their regional offices or between agencies as was recommended in the letter of understanding. As a consequence, UNICEF and UNFPA headquarters staff both organized regional meetings in Africa in 2007, with the same countries as participants, but with no coordination between the two agencies.

\section{CONCLUSION}

In summary, FRONTIERS did manage to support the first year of activities of the Interagency Coordination Group. In particular, staff assisted the group in networking, learning to talk to each other, setting up an operational way of functioning, and influencing key international policy and programmatic documents. In addition, lessons learned through OR on FGM/C were disseminated widely through the group's activities and FRONTIERS technical assistance influenced several plans of action and implementation programs. Beyond some effort in better networking for presenting a common regional vision during the development of policy and programmatic international documents, there is room for improving the collaboration between agencies. There is a need for more coordination and information sharing within each agency, particularly between headquarters and regional offices. 